\title{
SUPPORTING THE MODELLING AND MANAGING OF RELATIONS IN THE DESIGN PLATFORM
}

\author{
André, Samuel; Elgh, Fredrik \\ Jönköping University
}

\begin{abstract}
A common strategy which has in many cases become a necessity in product developing companies is to apply platform thinking to some extent. Engineer-to-order (ETO) companies are firms that need to invest in a significant amount engineering time in each product ordered by customers. These companies have in the past been known to not be fully able to apply platform strategies. An area of concern to product development is the design and manufacture of machine tools aimed for part manufacturing which is a large investment and a critical bottle neck. As a response to these challenges the design platform (DP) concept was developed which is founded on the re-use of company assets. This paper aims to investigate the application of the DP in a company designing and producing unique high-pressure die casting tools for different applications and customers. To enable companies of this character to utilize platform thinking to a higher degree and thus increase the efficiency in product development, a focus is set on modelling and managing relations within the DP. In addition, a PDM system setup is proposed together with an integrated support application for the realisation in industry.
\end{abstract}

Keywords: Platform strategies, High Pressure Die Casting, Product Lifecycle Management (PLM), Product modelling / models, Engineer-to-Order

\section{Contact:}

André, Samuel

Jönköping University

Industrial Product development, Production and Design

Sweden

samuel.andre@ju.se

Cite this article: André, S., Elgh, F. (2019) 'Supporting the Modelling and Managing of Relations in the Design Platform', in Proceedings of the 22nd International Conference on Engineering Design (ICED19), Delft, The Netherlands, 5-8 August 2019. DOI:10.1017/dsi.2019.307 


\section{INTRODUCTION}

A common strategy which has in many cases become a necessity in product developing companies is to apply platform thinking to some extent. The term platform thinking is mention in early publications (McGrath, 1995, Sawhney, 1998) where the whole firm is included when explaining the business opportunities. The platform thinking concept takes into consideration an array of different company assets as having the possibility to be reused and to build a common base in the company from which products can be efficiently developed, produced and launched (Meyer and Lehnerd, 1997). Engineerto-order (ETO) companies are firms that need to invest in a significant amount of engineering time in each product ordered by customers. Examples of ETO companies include suppliers of automotive and aerospace sub-systems and components, as well as custom engineered tools for casting and stamping machines. These companies cannot create standard modules to be configured upon request since future requirements are unknown and therefore the investment in a product platform is estimated as a high risk (Halman et al., 2003). The platform thinking concept, however, is a promising approach for these companies but few examples exist of actual methods to support an implementation of the concept.

As a response to the previously described challenge and opportunity, the design platform (DP) concept was developed based on the needs of engineering-to-order companies (André and Elgh, 2018, André et al., 2017) which, traditionally, have not been able to use product platform techniques such as modularisation. Besides physical components and modules, a DP is founded on the re-use of assets which can be of many different types and that often are ill-structured and un-formalized. This is in similar to the definition of a product platform as described by Robertson and Ulrich (1998): "A platform is a collection of assets that are shared by a set of products".

An area of concern to product and production development is the design and manufacture of machine tools aimed for part manufacturing. The design and manufacture of tools is often a large investment and is also a critical bottle neck in the development of a product. Changes in customer behaviour and market demands have resulted in an increasing number of product variants, decreased product life cycles and shorter time in product development. These factors have put high pressure on manufacturing companies and introduced a tough competition with low-wage countries (BührigPolaczek et al., 2017). Methods have for long been sought to make the process for tool design and manufacture quicker and more efficient, but due to high level of uniqueness and the expertise associated with designing the tools, not many examples are to be found. Modularity has been brought forward as a promising technique (Bührig-Polaczek et al., 2017), however, how commonality can be achieved from standardizing interfaces, in a relatively integral and highly customized product, is still a blank spot since an extreme uniqueness is expected of each machine tool. The distinction between what is a generic or a variant specific solution is also a challenge when development is conducted in customer focused projects. The lack of a platform model to cope with these challenges hinders the possibility of reusing the knowledge in upcoming projects.

Previous publications on the DP has mainly focused on the identification and modelling of assets into objects (André and Elgh, 2018, André et al., 2017). It has though been discovered that the relations between these asset objects play an important role and are to be considered as assets in themselves. The relations have the possibility to communicate how and in what order assets can be used. The aim of this paper is to investigate the application of the DP in a company designing and producing unique high-pressure die casting (HPDC) tools for different applications and customers. To enable companies of this character to utilize platform thinking to a higher degree and thus increase the efficiency in product development, a focus is set on modelling and managing relations within the DP. In addition, a PDM system setup is proposed together with an integrated support application for the realisation in industry.

This research has been conducted within a joint industry-academia project executed in close collaboration with five companies concerning how HPDC tool design can become more efficient and take advantage of the progress in the area of additive manufacturing (AM) and digitalisation. The companies consist of:

1. A supplier of systems and knowledge for AM.

2. A company that manufactures advanced cast aluminium.

3. A company that is supplier of PDM-solutions based on an in-house developed system.

4. A company that are currently developing their business offer towards design and manufacture of 
highly customized components produced in very small volumes.

5. A company that designs and manufactures tools for HPDC. The company needs new methods and tools for increased customization, shorter development lead times and quicker introduction of new products on the market.

The overall starting-point in industrial challenges is in accordance with problem-based research and the project research scheme is based on the design research methodology (DRM) (Blessing and Chakrabarti, 2009). This includes the introduction, evaluation, and refinement of new concepts as prescriptive methods and models (Duffy and Andreasen, 1995). This paper is mainly based on a study at company 5. Several semi structured interviews have been conducted together with a joint study of company processes, resources and documentation. Prescriptive methods and models have been introduced and incorporated in a computer application that has been developed, employed and discussed with the company using company specific data.

\section{FRAME OF REFERENCE}

Platform strategies, as a means for customization, have become a common strategy in the industry to serve many products while maintaining business efficiency. Research on product platforms has focused on efficiently providing the market with a product variety while also keeping internal variation low and in that way reach a higher level of standardization of the production (Meyer and Lehnerd, 1997). Platforms have also served as a way to reach different customer segments efficiently and simultaneously by featuring commonality in product interfaces and through branding. The concept of "product platform" seems to have been termed somewhere during the eighties. However, platform thinking (Sawhney, 1998) including reuse, component standardization and commonality (Guerrero, 1985) have probably been practiced by design engineers long before the obvious business possibilities was discovered and systematized. The authors of (McGrath, 1995, Sawhney, 1998) identify the business opportunities of platform thinking and include the whole firm in the mindset. These publications, however, lack the detailed support for firms to gain the direct benefits of platform thinking. Today, platforms are used on several levels in companies from early phases of design, as an architect tool, to business tools used for branding in the consumer market. However, the discussion regarding how ETO companies, like tool manufacturers, can benefit from a platform approach seems to just have been started. There is, therefore, a lack of research that describes how these companies can reap the rewards of platform thinking when the rigidity associated with standardized interfaces and pre-planned variants is not an option. The reduction of the number of offered variants (Vollmar and Gepp, 2015) is not a possibility for these companies since their competitive edge often lies in the ability to offer unique products.

\subsection{Platform approaches in the high-pressure die casting tooling industry}

According to Bührig-Polaczek et al. (2017), the HPDC process is the dominating casting process for aluminium components. In 2011, it accounted for more than $50 \%$ of all aluminium casted parts in Germany, with the automotive industry being its main customer. Therefore, the growing demand for more unique products is a major challenge for both HPDC and the automotive industry. The complexity of addressing this development comes from the fact that the HPDC process is a mouldbased production process. The HPDC process is therefore strongly influenced by die cost and design. The high investment costs for the dies have for a long time restricted the process to products that are needed in large volumes. For these reasons the volume of literature concerning increasing efficiency of HPDC tooling design is scarce. Queudeville et al. (2014) investigates the possibility and approach for modularizing HPDC dies. Their method is composed of three phases: initiation, analysis, and design phases. During these phases, the focus is narrowed down from the company view via die perspective to die component perspective. By consecutively proceeding through the phases, the stages of the production process where a modularization is most beneficial is identified. Die components can then be categorized according to their modularization potential. The final phase determines how a chosen die component is turned into a module. Queudeville et al. (2011) propose that certain properties of a component are standardized whereas others stay individual. The proposed methodology consists of three phases with three different levels of detail. Stolt et al. (2018) investigates how additive manufacturing can be utilized for HPDC tools in order to reach a higher level of modularization and decreased cost and tool manufacturing lead time. They conclude that a direct 
application of AM to HPDC inserts is not beneficial. The ways of designing the insert must be vastly different from the traditional ways in order to decrease the mass and thus the time used for printing.

\subsection{The design platform approach}

The DP (André et al., 2017) was created as a response to the lack of platform models for ETO companies; especially as a means to increase the reuse of company assets in environments where requirements fluctuate during the development. A DP is composed of different objects related to Process, Synthesis Resources, Product Constructs, Assessments Resources, Solutions, Projects and Constraint. These objects can be, but are not limited to, physical parts since design reuse can be practiced on an array of different types of embodied knowledge. When there is no possibility of reusing geometry, there is often a way to apply guidelines, process descriptions, calculations etc. which are associated with the type of generic product item (GPI) they concern. The GPIs embodies the generic parts of the product and the structure. This essentially creates a coherent platform description consisting of heterogeneous assets which are allowed to evolve over time and also enables reuse.

\section{MODELLING AND MANAGING RELATIONS IN THE DESIGN PLATFORM}

A relation, is in this paper, referred to as an object which connects two other objects and holds information about why and of which nature the connection is. Figure 1 shows a class relationship scheme of the DP constituents and how a generic product containing a generic product item structure holds constructs of different types. The Relation class can be of different types and essentially relates the different construct types to each other. A relation object holds rational of why the relation exist and what type of relation it is.

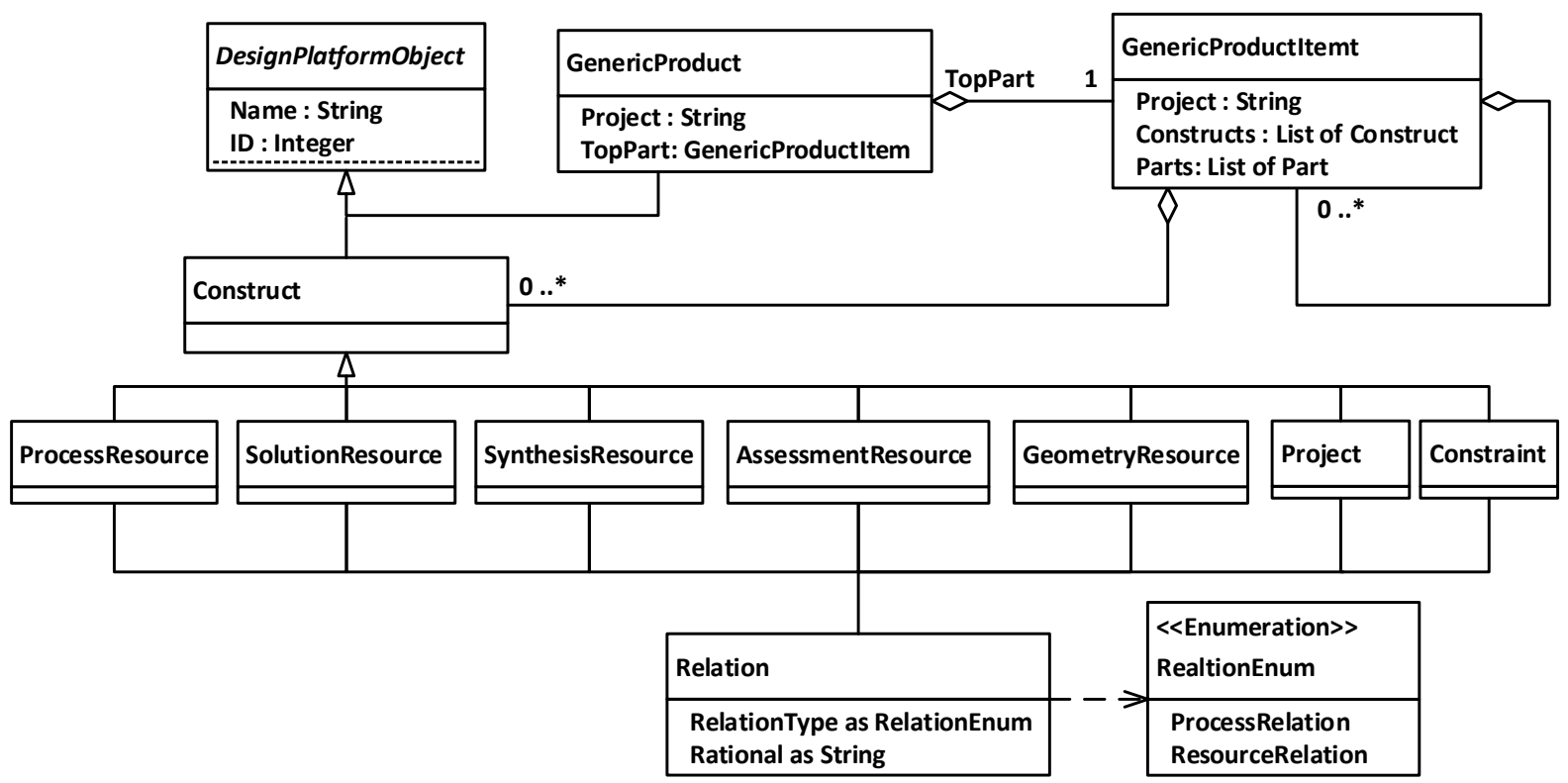

Figure 1. Generic class relationships of the DP

The process of defining a DP concern, among other steps, the identification, formalization and publication of assets as objects. After identification, the objects are to be structured and associated with one or several GPI and process steps that has been mapped in the process. This structure essentially creates hierarchical relations between the objects and the different GPIs. This in turn generates a view focused on how the assets relate to the general product and process. However, in order to support the use phase of the DP, additional relations are needed. These additional relations aim to support the process of using the objects together on a detailed level. For this purpose, a generic asset relationship matrix is proposed to support the modelling of the relations between objects within and between the different asset domains.

Multiple relations exist between assets which cannot be modelled using only the product structure tree. The relations which become obvious in the tree structure are hierarchical and focus on how systems are grouped together. Within and between groups of hierarchical levels, additional guidance is needed e.g. to support in what sequence to perform activities or which knowledge that can be used as a 
resource in a process. The matrix is composed of inter-domain DSMs for modelling relationships between objects of the same type, and multi-domain matrices (MDM) where objects are of different types. The generic relationship matrix is shown in Figure 2 with illustrative relations. The relationships that are connecting

the different objects are objects themselves and instantiated from the following types:

- Process relationships ( $P$ in Figure 2) states sequence order of objects. It foremost refers to the order in which a set of activities or process steps should be executed.

- $\quad$ Resource relationships ( $R$ in Figure 2) states if a certain object is to be used as a resource for another object. E.g. an object describing a parametric CAD model can be a resource for an object describing an activity concerning the design of a specific component.

- Hierarchy relationships (H in Figure 2) are derived from the tree structure and are not an explicit relationship type in the class diagram (Figure 1) since it is implicitly existing in the aggregation relationship of the GPI class.

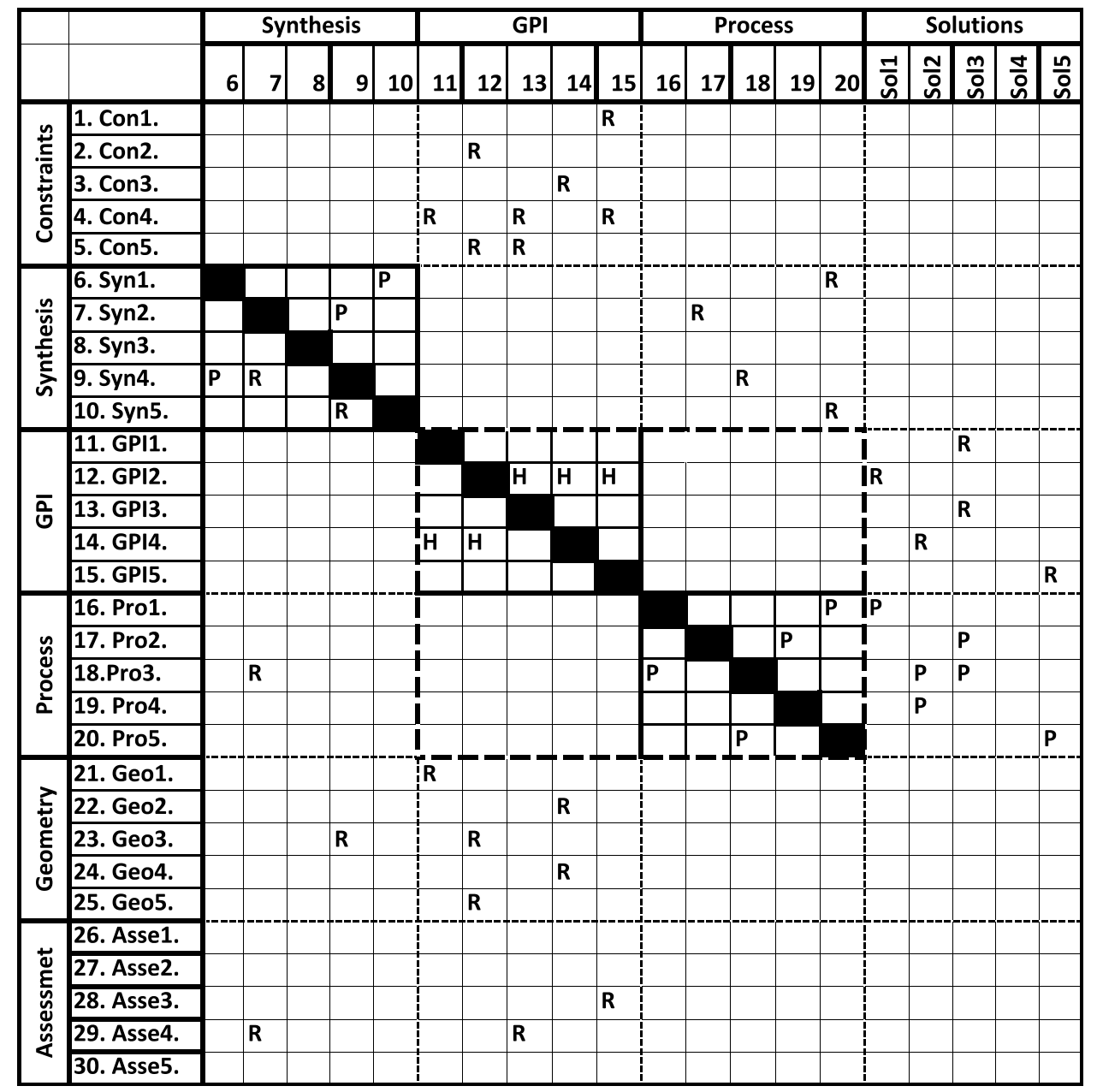

Figure 2. Generic relationship view of the DP

The objects that populate the rows and columns in the matrix are either input, output or intermediate objects used in the process. Constraints are regarded as the input to the process since they embody both customer requirements and internal constraints that create the limits within which the finished solution is valid. They do therefore not have a domain since they do not relate directly to each other but rather indirectly through the solutions that are the output of the design process. This is reflected by not having numbered columns corresponding to the row numbers. Similarly, no intra-domain DSMs exist for geometry and assessment resources since they also are considered as supportive resources to other objects. Neither solution resources can be directly related to each other and thus do not have an intra-domain DSM. All objects which are placed on rows are to be considered as template objects. Their specific instances are considered as solutions and can be located in the last columns which are the output from the different process stages. Each row object will thus have a solution connected to it. 
The final product structure is described by the GPI structure. The remaining domains are explained in the following:

- $\quad$ Synthesis resource domain: This domain consists of all the resources used for design synthesis which have been retraced and formalized. Within the domain, Process, Resource or Hierarchy relationships can be used to either specify the specific execution order of the activities, if a synthesis resource is needed for the fulfilment of another or if a synthesis resource is split into sub-resources.

- GPI domain: This domain states the hierarchical relationships between generic product items and thus embody the generic product structure to which other resources are attached. This view together with the process domain constitutes the core of the matrix and together forms a generic view of both the product and the process which can be related to each other and to other resource objects.

- Process domain: This domain describes the Process relationships between process steps and milestones which have been formalized and generalized. These are essentially placeholders to be related to other types of objects via MDMs.

- Multi domain matrices: The MDMs are used for mapping relationships in between the different objects of different domains. The possibilities become many, but in general, there are three parts: inputs, outputs and intermediate supportive object relationships. The Part and the Process domain are the core of the relationship view and either require an input, output or both.

Essentially the asset relationship matrix provides a possibility to model relationships between the objects that exist within a specific DP. This creates a coherent overview of the heterogeneous content included in the DP which makes it possible to manage assets of different disciplines in one view. Ultimately this allows for different kinds of analyses to be applied to the matrix, to e.g. investigate change propagation, but also to be proactive in development to make sure that the right things are considered in the right order. It also provides a rational which can be revisited when maintaining company assets.

\section{CASE OF APPLICATION}

The DP approach with the associated asset relationship matrix was employed at a company designing and manufacturing tools for HPDC. The performance requirements on the tool are immense due to the high pressure and temperature of the aluminium melt which is entering the tool at a very high speed. Due to the integral nature and the high level of customization of the tool, design efficiency by standardizing of components is limited. The company today work without any product data management (PDM) support. However, support exists in terms of CAD templates which contains some design automation that aid the designer to find parting lines and to place bushing holes. Some standard components, such as ejector pins, can also be bought directly from a supplier. An issue for the company is that they are not involved in the development of the part to be manufactured by the part manufacturer. Thus, they can never plan the tools ahead of a customer order since the future part to be manufactured is unknown and each project is unique. The business relations prohibit the company from being included in the development of the part (Figure 3). In reality, the company often receives a request for quotation (RFQ) of a part which is not optimized to be casted. Several iterations follow where the company gives input to the OEM to adapt the part to be casted. This work can most often not be charged and essentially prohibits the company to proactively develop their tools to efficiently respond to RFQ and to design and manufacture the order. In many cases it is the part manufacturer that orders, uses and stores the tool while the OEM owns the design of the part and the tool.

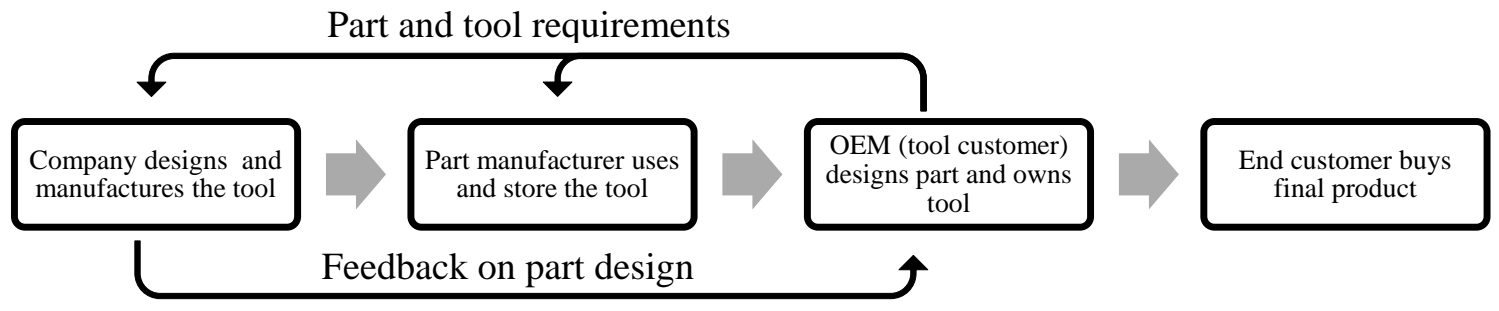

Figure 3. Early business relation between tool designer, tool manufacturer and customer 


\subsection{Applying the DP approach}

Even though the level of formalisation of methods and design guidelines was low at the company, they could be identified and formalized using standardized templates. The work was accomplished through a set if semi structured interviews, demonstrations and reviews of company documents. The main parts of the process are explained in the following.

A HPDC tool is often categorized as an integral product, however, several parts are needed to get a functioning tool. Through interviews and by examining tools currently in production as well as tools that had been produced in the past, generic parts could be identified. Most often not all parts are included in a specific tool. The part design determines the level of complexity of the tool and thus how many of the parts that are needed. The following generic parts could be identified:

- $\quad$ Ejector side: Support plate, ejector box, ejector plate, ejector pin, ejector retaining plate, ejector die, leader pin bushing.

- Cover side: Core insert, spreader, cavity insert, cover die, sprue bushing, leader pin, runner

- Slide: Slide lock, slide-angle pin, core slide header

The DP approach requires that certain actions are taken. Thus, after setting up management of the platform and having identified GPIs and analysed the generic system, associated assets are to be identified, formalized and published. The first thing to be formalized was the overall process of designing the tools. A simplified version can be seen in Figure 4.

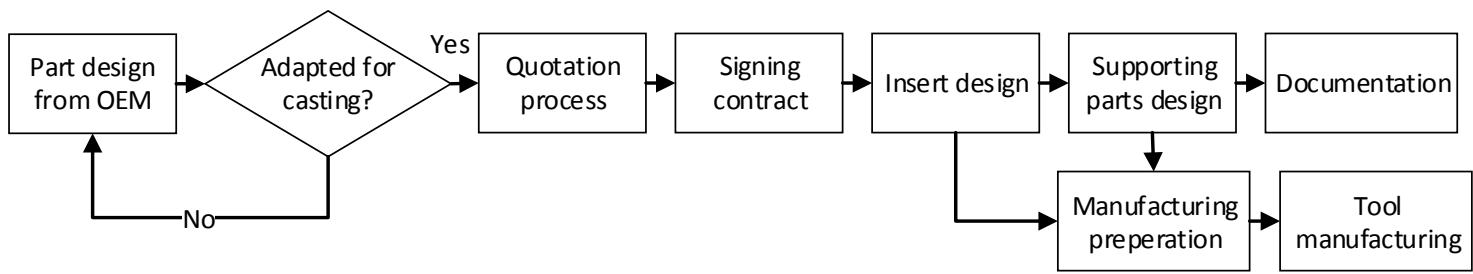

Figure 4. Main steps of the tool design process

The process starts by an OEM or part manufacturer supplying the company with a part design. The part is usually not adapted for casting and must thus be adapted by iterating the component back and forth with the OEM. Once the part is approved by the company the quotation process is initiated. This process concerns making rough calculations regarding material volume and design time resulting in a price. A preliminary tool design with a low level of detail is produced. When the quote is accepted by the customer, a contract is signed and the detailed design of the insert is started. This part requires the longest manufacturing time due to the required milling both before and after hardening. When finished the design is handed over to manufacturing. During manufacturing of the insert any slides are designed followed by supporting parts. The process ends with documentation of the project using 2D drawings. The DP approach proceeded by identifying assets of the classes constraint, synthesis resource, assessment resource, geometry resource and solution. A selection of these can be seen in Table 1 .

Table 1. A selection of identified assets

\begin{tabular}{|l|l|l|l|l|}
\hline Constraint & Synthesis & Assessment & Geometry & Solution \\
\hline Cycle time & Calc. material & Heat transfer approx. & UDF Cover die & Cover_insert.prt \\
\hline Melt temperature & Design parting line & Flow sim. & UDF ejector die & Core_slider.prt \\
\hline Tool leakage & Estimate manuf. time & Material volume & UDF Pin bushing & Cover_die.prt \\
\hline Component mass & Place ejector pins & & UDF runner & Ejector_die.prt \\
\hline Machine dimensions & Calc. proj. pressure & & UDF slide & Ejector_pin.prt \\
\hline Shrinkage & Design ingate sys. & & & Runner.prt \\
\hline Life & Design repl. parts & & Contract.docx \\
\hline
\end{tabular}

\subsection{Modelling and managing assets and relations using a DP support tool}

In order to realize the concept of an asset relationship matrix, a computer support tool with an integration to a PDM system was developed. The application reads the PDM system database which makes it possible to access and work on the same data. The objects in the matrix are selected from a database interface where the user classifies them regarding what type of assets they are. In order to construct the matrix, the objects identified in the previous step needs to be saved or created in the PDM system. Figure 5 shows how some of the objects are visualised in the PDM system. 

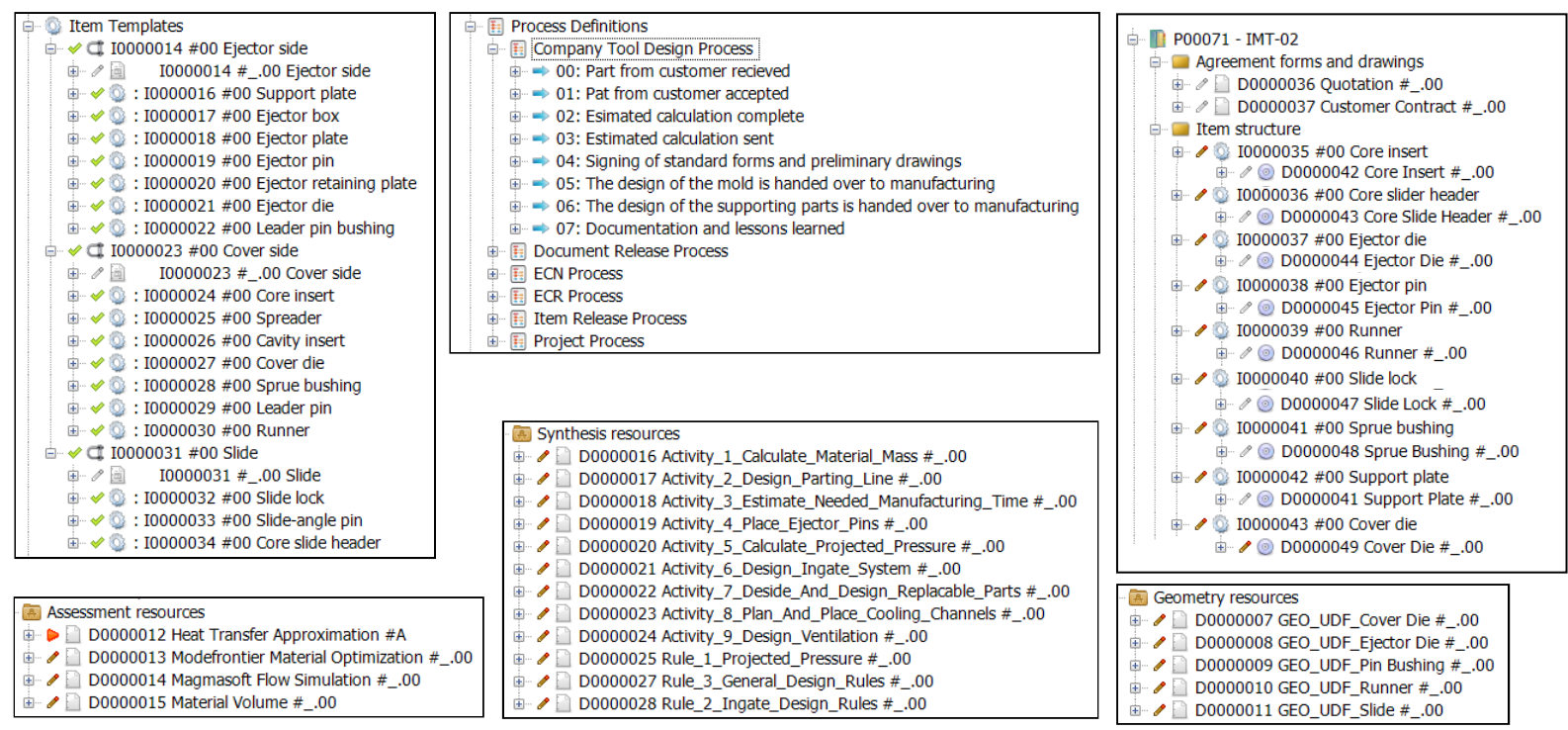

Figure 5. Screenshot of the visualisation in the PDM system

Figure 6 shows the interface of the developed application with an example matrix. The matrix is simplified regarding the number of objects which are visualised. The user can choose and classify the objects using the interface. The matrix can thereafter be automatically constructed grouping objects of the same type and colouring them for easy identification. Hierarchical relations can be directly read from the database while resource and process relations are manually created by the user. Constraints can act as inputs to GPI. This might not always be possible for all kinds of products which is why it is also possible to apply constraints to the process domain as well. For example, there might be requirements regarding certification tests that needs to be performed in a certain step of the process. The synthesis domain contains two relations. One specifies that the activity "Design parting line" acts as a resource to "calculate projected pressure" and the other states that "Place ejector pins" precedes "Place cooling channels". The GPI domain visualises a simple product structure where four items are grouped below the "Ejector side" item. The process domain contains five sequential steps. Solutions that, in this case, consist of geometry models are related to GPI. The solutions that relates to the process domain are formatted text documents specifying the contract and agreement. There are also two instances of assessment resources regarding "material volume calculation" and "heat transfer approximating".

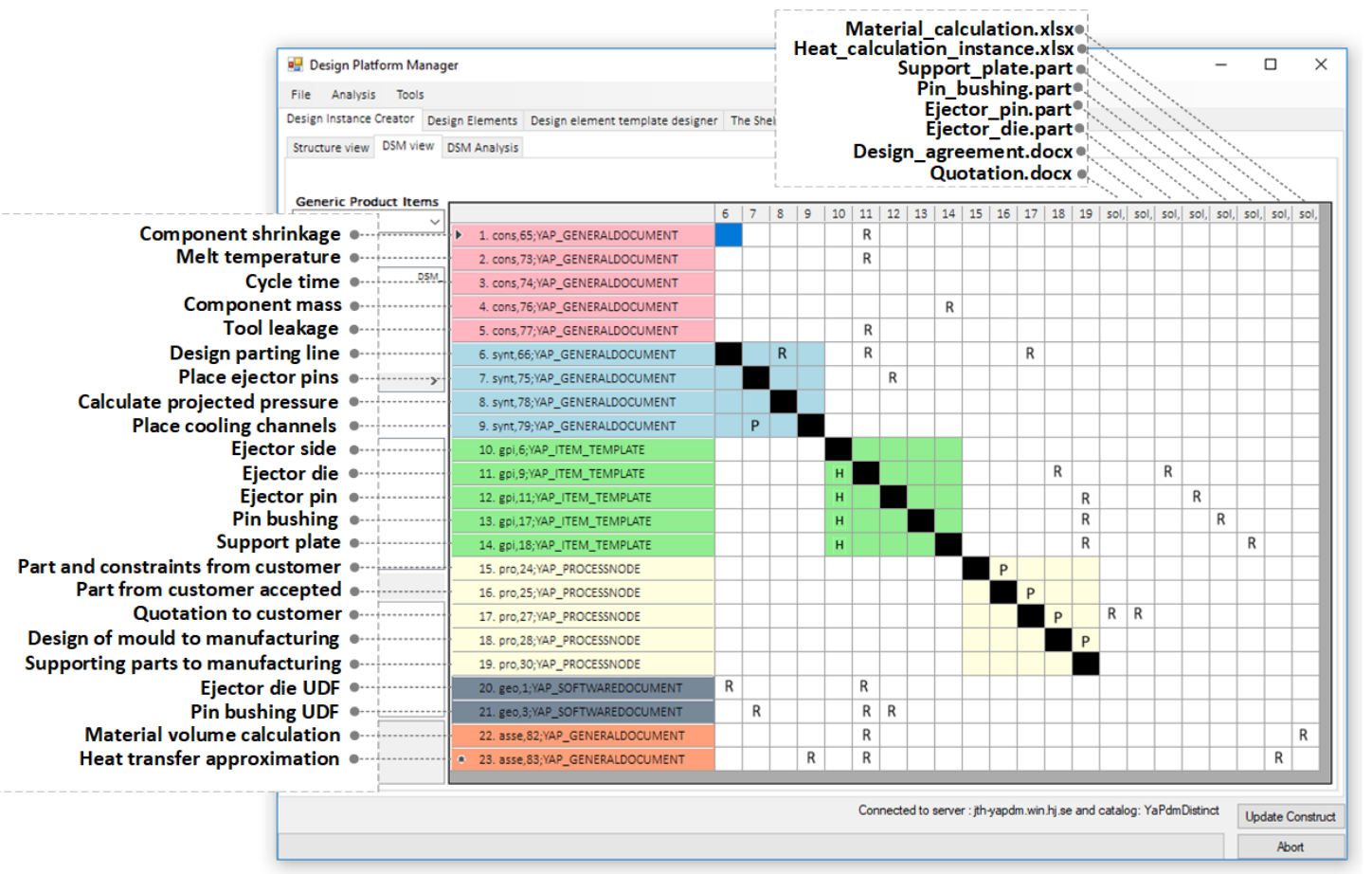

Figure 6. Screenshot of the asset relationship matrix in the application 
There are essentially three stages in the DP approach in which the matrix can support the company: Modelling, execution and maintenance.

- Modelling is supported since the company receives a format which they can use to formalize their assets, such as items, processes, tools and know how. For the case company it meant that they could capture and publish assets according to the DP approach. Moreover, they could structure the objects in a PDM system according to the generic structure of a HPDC die. The company could then associate the product to the process through the matrix.

- Execution is supported since the model can act as a map, guiding the engineers to applicable knowledge which essentially can guarantee a higher level of quality and shorter lead time. When a customer contacts the company, they can look at the matrix to guide them to the specific geometry

resources and assessment resources that supports them in creating a quote. When the detailed design is initiated, synthesis resources such as "Design parting line" and "Place ejector pins" can be used to make sure that the know how is reused and that they comply to standards.

- Maintenance is supported since the model can be used for change analysis. The model provides rational and traceability for future changes and product updates. In the company case, a change in e.g. the requirement "Cycle time" could affect the design of the ingate system or the component mass which is made explicit through the matrix.

\section{DISCUSSION}

This paper has provided a concrete approach to apply platform thinking as described by e.g. (Sawhney, 1998) by the means of DP. When introducing the DP in a company the possibilities regarding how it is to be applied becomes many. How in terms of: What parts are to be considered, what assets and company disciplines can be incorporated, what level of detail is the correct one? These questions can only be answered with the specific company of application in mind. Different types of products and business models provides different opportunities for DP application. This also applies to the asset relationship matrix. The matrix can be constructed as a management tool, including the primary business processes, primary customer requirements and so on. It can also be applied on a detailed level in a specific product development category or team within a company, connecting all specific assets used daily. It is here important to notice that these two levels have a connection and that the detailed level is part of the more abstract management level. For a specific product, the number of rows in the matrix can be kept static, as a template. The solution columns can be populated as the project proceeds. In this way a clear distinction is made between what is generic and what is variant specific and how these relate two each other. The generic product and separated process view makes it possible to either work process or product based. Depending on what role one has in the company, this opens several possibilities. This also becomes powerful depending on what type of business model the company applies.

- If the company applies a configure-to-order approach, then there can be an increased focus on the GPI domain and the synthesis resources describing configuration rules.

- If the company applies an ETO approach or if the product is integral, a higher focus on the process is suitable. The process is in turn connected to other kinds of assets to support the design process.

The matrix provides an overview of the system and the process used for creating it, starting from requirement and ending with solution. This in turn makes it a suitable tool for analysing changes that happen either during development or product maintenance. If a change is enforced to a component due to e.g. lack of quality, it becomes possible to analyse the interrelated parts and what assets that can be applied to make the change in a correct way or what assets that where incorrect and need changing. On the other hand, if a requirement is changed during the development, it becomes possible to analyse what implications the change has, what parts are affected and what assets can be applied to respond to the change. The matrix can potentially be used for analysing the level of platform support. A small matrix or a small number of relations could e.g. indicate that little is known regarding the product. A very large matrix with several relations can on the other hand mean that the overview is lost which can be interpreted as a need for dividing or filtering the matrix into smaller parts. 


\section{CONCLUSION}

The aim of the paper is to support ETO companies to become more efficient by the use of a platform approach. Especially, companies in the HPDC tooling business have been in focus. The DP approach supported by the relationship matrix enables the modelling of process and resource relationships between assets, both at a generic and a variant level. This ultimately provides an overarching and connected image of the product, process and assets to be used. The prototype application has been applied to company-specific data and verified throughout the research project. It has been presented and discussed with the company representatives. The matrix format provides possibilities to further create networks visualizing how parts, processes and assets relate. This in turn provides possibilities for the future to use clustering and other graph- and layouting techniques to further analyse the product portfolio. When the application has been used for a certain amount of time there also exist possibilities to add logic in order for the application to propose suitable courses of action depending on the input of the user. The application and associated method will be applied and tested in more companies to further strengthen generalisability, usefulness, and applicability.

\section{REFERENCES}

André, S. and Elgh, F. (2018), "Modeling of transdisciplinary engineering assets using the design platform approach for improved customization ability", Advanced Engineering Informatics, Vol. 38, pp. 277-290. https://doi.org/10.1016/j.aei.2018.07.006

André, S., Elgh, F., Johansson, J. and Stolt, R. (2017), "The design platform-a coherent platform description of heterogeneous design assets for suppliers of highly customised systems", Journal of Engineering Design, pp. 1-28. https://doi.org/10.1080/09544828.2017.1376244

Blessing, L. T. and Chakrabarti, A. (2009), DRM, a design research methodology: Springer. https://doi.org/10.1007/978-1-84882-587-1_2

Bührig-Polaczek, A., Behr, M., Hopmann, C., Schuh, G., Aryobsei, A., Elgeti, S. and Schmidt, F. (2017), "Mold-Based Production Systems", In Integrative Production Technology. Springer. (pp. 113-174) https://doi.org/10.1007/978-3-319-47452-6_3

Duffy, A. and Andreasen, M. (1995), "Enhancing the evolution of design science", Proceedings of ICED 95: International Conference on Engineering Design, Praha, Czechoslovakia August 22-24, 1995.

Guerrero, H. H. (1985), "The effect of various production strategies on product structures with commonality", Journal of Operations Management, Vol. 5 No. 4, pp. 395-410. https://doi.org/10.1016/02726963(85)90021-x

Halman, J. I. M., Hofer, A. P. and Vuuren, W. V. (2003), "Platform-driven development of product families Linking theory with practice", Journal of product innovation management, pp. 149-162. https://doi.org/10.1111/1540-5885.2002007

McGrath, M. E. (1995), "Product strategy for high-technology companies", Irwin professional publishing, New York. https://doi.org/10.1108/ws.2001.07950dae.002

Meyer, M. H. and Lehnerd, A. P. (1997), "The power of product platforms - Building value and cost leadership”, The Free Press, New York. https://doi.org/10.1016/s0737-6782(97)80157-9

Queudeville, Y., Ivanov, T., Vroomen, U., Bührig-Polaczek, A., Elgeti, S., Probst, M. and Nussbaum, C. (2011), "Design methodology for modular tools", Production Engineering, Vol. 5 No. 4, pp. 351-358.

Queudeville, Y., Vroomen, U. and Bührig-Polaczek, A. (2014), "Modularization methodology for high pressure die casting dies", The International Journal of Advanced Manufacturing Technology, Vol. 71 No. 9-12, pp. 1677-1686. https://doi.org/10.1007/s00170-013-5582-9

Robertson, D. and Ulrich, K. (1998), "Planning product platforms", Sloan Management Review, Vol. 39 No. 4, pp. 19-31.

Sawhney, M. S. (1998), "Leveraged high-variety strategies: from portfolio thinking to platform thinking", Journal of the Academy of Marketing Science, Vol. 26 No. 1, p. 54. https://doi.org/10.1177/0092070398261006

Stolt, R., André, S. and Elgh, F. (2018), "Introducing Inserts for Die Casting Manufactured by Selective Laser Sintering", Procedia Manufacturing, Vol. 17, pp. 309-316. https://doi.org/10.1016/j.promfg.2018.10.051

Vollmar, J. and Gepp, M. (2015), "Framework for standardization programs in the Engineer-To-Order industry", Management of Engineering and Technology (PICMET), Portland, 2015.

https://doi.org/10.1109/picmet.2015.7273186

\section{ACKNOWLEDGEMENTS}

This article was supported by the KK foundation for the DISTINCT project. The authors would like to express their sincere gratitude to the funding agency as well as the case company for sharing invaluable knowledge. 